\title{
C-C motif chemokine 14 as a novel potential biomarker for predicting the prognosis of epithelial ovarian cancer
}

\author{
YUBO CAI $^{1 *}$, YIHONG LING $^{2,3^{*}}$, LINGBO HUANG $^{4 *}$, HUI HUANG $^{1}$, XIANLAN CHEN $^{1}$, \\ YONGBO XIAO ${ }^{2,3}$, ZHONGMEI ZHU ${ }^{2,3}$ and JIEWEI CHEN ${ }^{2,3}$ \\ ${ }^{1}$ Department of Pathology, Jiangmen Central Hospital, Jiangmen, Guangdong 529200; \\ ${ }^{2}$ State Key Laboratory of Oncology in South China, Collaborative Innovation Center for Cancer Medicine; \\ ${ }^{3}$ Department of Pathology, Sun Yat-Sen University Cancer Center, Guangzhou, Guangdong 510060; \\ ${ }^{4}$ Department of Gynecology, Huazhou People's Hospital, Huazhou, Guangdong 525100, P.R. China
}

Received November 13, 2019; Accepted December 19, 2019

DOI: $10.3892 / \mathrm{ol} .2020 .11378$

\begin{abstract}
Previous studies have demonstrated that C-C motif chemokine 14 (CCL14) plays an important role in the occurrence and development of cancer. However, the significance of CCL14 in the progression and prognosis of epithelial ovarian cancer (EOC) has not yet been reported. The standard EnVision procedure for tissue microarrays was used to evaluate the immunohistochemical expression of CCL14 protein in 154 patients with EOC who underwent tumor-debulking operations at the Central Cancer Department of Sun Yat-Sen University (Guangzhou, China) or Jiangmen Central Hospital (Jiangmen, China). The association between CCL14 expression and clinicopathological variables was assessed using the $\chi^{2}$ test. For survival status of patients with EOC, Kaplan-Meier survival analysis and a Cox multivariate regression model was used. Expression of CCL14 protein was significantly associated with International Federation of Gynecology and Obstetric stage $(\mathrm{P}=0.014)$ and $\mathrm{pN}$ status $(\mathrm{P}=0.005)$. Kaplan-Meier survival analysis revealed that the survival time of patients with high expression of CCL14 was 136.1 months and that of patients with low expression of CCL14 was 98.9 months $(\mathrm{P}=0.026)$. Multivariate analysis demonstrated that CCL14 upregulation was associated with overall survival time (HR, $0.48 ; 95 \% \mathrm{CI}, 0.261-0.896 ; \mathrm{P}=0.021)$ and progression-free survival time (HR, $0.437 ; 95 \% \mathrm{CI}, 0.228-0.839 ; \mathrm{P}=0.013)$. In conclusion, CCL14 is an independent prognostic factor for EOC and upregulation of CCL14 is associated with a more favorable prognosis in patients with EOC.
\end{abstract}

Correspondence to: Dr Jiewei Chen, Department of Pathology, Sun Yat-Sen University Cancer Center, 651 Dong Feng Road East, Guangzhou, Guangdong 510060, P.R. China

E-mail: chenjiew@sysucc.org.cn

*Contributed equally

Key words: epithelial ovarian cancer, C-C motif chemokine 14, prognosis

\section{Introduction}

In 2018, 22,240 cases of epithelial ovarian cancer (EOC) were reported in the United States of America, with the associated death toll being 14,070 individuals (1). EOC is the primary cause of death from gynecological cancer in the US, with the morbidity and mortality being $11.5 / 100,000$ and $6.7 / 100,000$, respectively (2). The findings of EOC are usually advanced, and the 5-year survival rates for EOC diagnosed at stages III and IV are only $41 \%$ and $20 \%$, respectively, in the United States (2). Histologically, EOC can be divided into 4 types: Serous carcinoma (68-71\%), endometrioid carcinoma (9-11\%), clear cell carcinoma (12-13\%) and mucinous carcinoma $(3 \%)(3,4)$. Studies have revealed that EOC is a heterogeneous tumor $(5,6)$. The current standard treatment for EOC consists of cytoreductive surgery and platinum-based chemotherapy (7). Despite aggressive treatment, overall survival rate (OS) has not significantly improved in recent decades $(8,9)$. Therefore, novel therapeutic targets are required to improve the current prognosis of patients with EOC.

In recent years, numerous studies have demonstrated that the tumor microenvironment plays an important role in the progression and metastasis of cancer $(10,11)$. Chemokines are important members of the tumor microenvironment and mediate the recruitment of immune cells to the tumor microenvironment (12). Thus, chemokines are directly and indirectly involved in the formation of the tumor environment and immune milieu (13). C-C motif chemokine 14 (CCL14) is an important member of the chemokine family and was originally isolated from blood filters of patients with chronic renal failure. The protein is composed of 74 amino acids, of which 4 cysteine residues are linked by disulfide bonds (14). The relative molecular weight of CCL14 is $8,673 \mathrm{kDa}$ and it has $46 \%$ sequence homology to macrophage inflammatory protein (14). CCL14 specifically binds to chemokine receptor 1 (CCR1), CCR3 and chemokine receptor 5 (CCR5) to exert biological effects $(15,16)$. A previous study in patients with breast cancer have demonstrated that CCL14 promotes angiogenesis and metastasis (17). It has also been reported that CCL14 is involved in the occurrence and development of oral cancer (18). Therefore, the biological functions of CCL14 are diverse. The 
involvement of CCL14 in the formation of the immune microenvironment indicates that the CCL14/CCR1/CCR5 axis can be used as a potential target for immunotherapy. The underlying mechanism of action of CCL14 in EOC is unclear and the significance of CCL14 in the progression and prognosis of EOC has not been reported. The present study aimed to elucidate the role of CCL14 in EOC.

\section{Patients and methods}

Patient specimens. The Medical Ethics Committees of the Cancer Center of Sun Yat-Sen University (Guangzhou, China) and Jiangmen Central Hospital (Jiangmen, China) approved the present study. The requirement for patient consent was waived by the ethics committees. A total of 154 patients with EOC were enrolled between January 2008 and December 2015. The mean age of enrolled patients was 48.5 years, ranging from 17-86 years. Among these cases, 82 patients had undergone ovariectomy at the Central Cancer Department of Sun Yat-Sen University and 72 patients had undergone ovariectomy at Jiangmen Central Hospital. The inclusion criteria for these patients in the present study were: Tissues could undergo immunohistochemical examination; no history of chemotherapy, radiotherapy and surgery prior to ovariectomy; complete immune function; and no other malignant tumors or secondary primary tumors. The follow-up period was censored to December 2018. All cases were classified on the basis of the World Health Organization Classification of Tumors of Female Reproductive Organs (19), the Tumor Node Metastasis Classification System of the US Joint Commission (20). The stage of tumors was assessed according to the International Federation of Gynecology and Obstetrics (FIGO) (21). The positive control tissues in the present study were derived from adjacent renal tissue from the surgical specimens of patients with renal cancer, which were paraffin-embedded tissue specimens archived following pathological diagnosis.

Tissue microarray (TMA) and immunohistochemistry (IHC). The standard EnVision procedure for tissue microarrays was used to evaluate the immunohistochemical expression of the CCL14 protein (22). To avoid potential bias caused by the heterogeneity of tumors, the TMA included 154 patient samples and each sample had 3 selected points with a diameter of $1.5 \mathrm{~mm}$. IHC was performed on all points for each sample. The results of IHC were calculated by averaging the 3 points. All samples were fixed with $10 \%$ neutral buffered formalin (NBF) at room temperature for $48 \mathrm{~h}$. IHC sections were prepared using 3- $\mu$ m TMA paraffin-embedded sections. Xylene was used to de-wax the sections and then the sections were rehydrated in a descending alcohol series (100, 95, 85, 75 and 65\%) and distilled water at room temperature. Subsequently, the sections were pressure-cooked at $100^{\circ} \mathrm{C}$ with citric acid buffer solution ( $\mathrm{pH}$ 6.0) for $3 \mathrm{~min}$ to repair antigen, then sections were placed in $3 \%$ hydrogen peroxide for $10 \mathrm{~min}$ to block endogenous peroxidase activity. After the pre-processing in the aforementioned steps, TMA sections were incubated with CCL14 primary antibody (polyclonal antibody; cat. no. PA5-28819; Invitrogen; Thermo Fisher Scientific, Inc.) at a dilution ratio of $1: 500$ for $50 \mathrm{~min}$ at $37^{\circ} \mathrm{C}$ in the incubator. Following this, TMA sections were incubated with CCL14 secondary antibody (undiluted; cat. no. K5007; Dako; Agilent Technologies, Inc.) for $30 \mathrm{~min}$ at $37^{\circ} \mathrm{C}$ in the incubator. The sections were then stained with 3,3-diaminobenzidine. The last step involved using hematoxylin to counterstain the sections, which were finally fixed using dehydration. Human kidney tissue was used as the positive control (14) and in the negative control, human kidney tissue were incubated with $0.02 \mathrm{~mol} / 1 \mathrm{PBS}$ instead of the primary antibody against CCL14.

IHC evaluation. Expression levels of CCL14 was evaluated by 2 independent pathologists using a light microscope (cat. no. BX51; Olympus Corp.). Percentages (0-100\%) were used to define the number of positive tumor cells and a scoring system was used to evaluate dye strength as follows: Negative expression, -; low positive expression, 1+; moderate positive expression, 2+; and strong positive expression, 3+. Scoring of each sample was performed using the following formula: Percentage of positive cells $x$ dye strength and the total score of each sample ranged from 0-300 (22).

Statistical analysis. SPSS v16.0 (SPSS, Inc.) was used to perform the statistical analysis of the present study. Data are presented as mean standard deviation. The $\chi^{2}$ test was used to analyze the association between CCL14 protein expression levels and clinicopathological parameters in patients with EOC. Survival analysis of patients with EOC was performed using the Kaplan-Meier method with the log-rank test for evaluation. A Cox proportional hazard model was used to perform multivariate analyses. All P-values were analyzed bilaterally. $\mathrm{P}<0.05$ was considered to indicate a statistically significant difference.

\section{Results}

Immunohistochemical analysis of CCL14 in tissues from patients with EOC. IHC results revealed that CCL14 was expressed in most cases, mainly in the cytoplasm of cancer cells. Representative image of expression levels are presented in Fig. 1, from negative to strong positive. IHC scoring showed that 17 cases were scored between 0-50 (11.04\%), 39 cases were scored between $\geq 50-100(25.32 \%) ; 22$ cases were scored between $\geq 100-150$ (14.29\%), 27 cases were scored between $\geq 150-200$ (17.53\%), 20 cases were scored between $\geq 200-250$ $(12.99 \%)$ and 29 cases were scored $\geq 250$ (18.83\%) (data not shown).

Cut-off value for CCL14 expression levels. In order to select the appropriate cut-off point of CCL14 for further analysis, a receiver operating characteristic (ROC) curve was used to analyze each clinicopathological parameter. The point of infinite proximity $(0.0,1.0)$ on the ROC curve for each clinicopathological parameter had relevant specificity and sensitivity at the highest points (23), so these areas were defined as the cut-off points. The ROC curve analysis demonstrated that survival status, FIGO stage, pN status and relapse were taken as state variables for ROC analysis (Fig. 2) and that the classification efficiency of survival status (area under curve, 0.612; $\mathrm{P}=0.02$ ) was the best (Fig. 2A). Therefore, survival status was taken as a state variable and 190 was defined as the cut-off point for CCL14 protein expression levels. High expression 

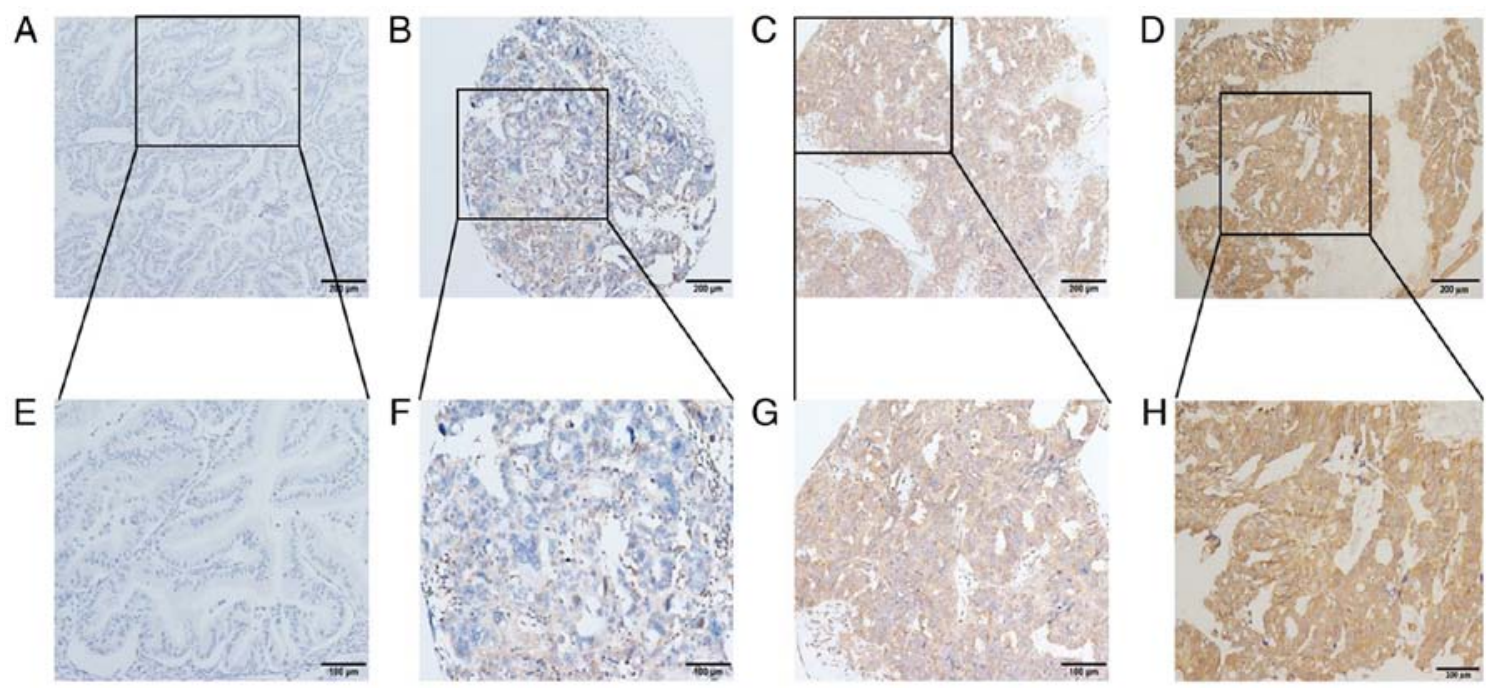

Figure 1. CCL14 protein expression levels in tissues from patients with epithelial ovarian cancer. (A) Negative expression (-), x10 magnification; (B) low positive (1+), x10 magnification; (C) moderate expression (2+), x10 magnification; and (D) strong expression (3+), x10 magnification. Images (E-G) and (H) represent the higher magnification (x20) from the area of the inset box in images (A-D), respectively. CCL14, C-C motif chemokine 14.
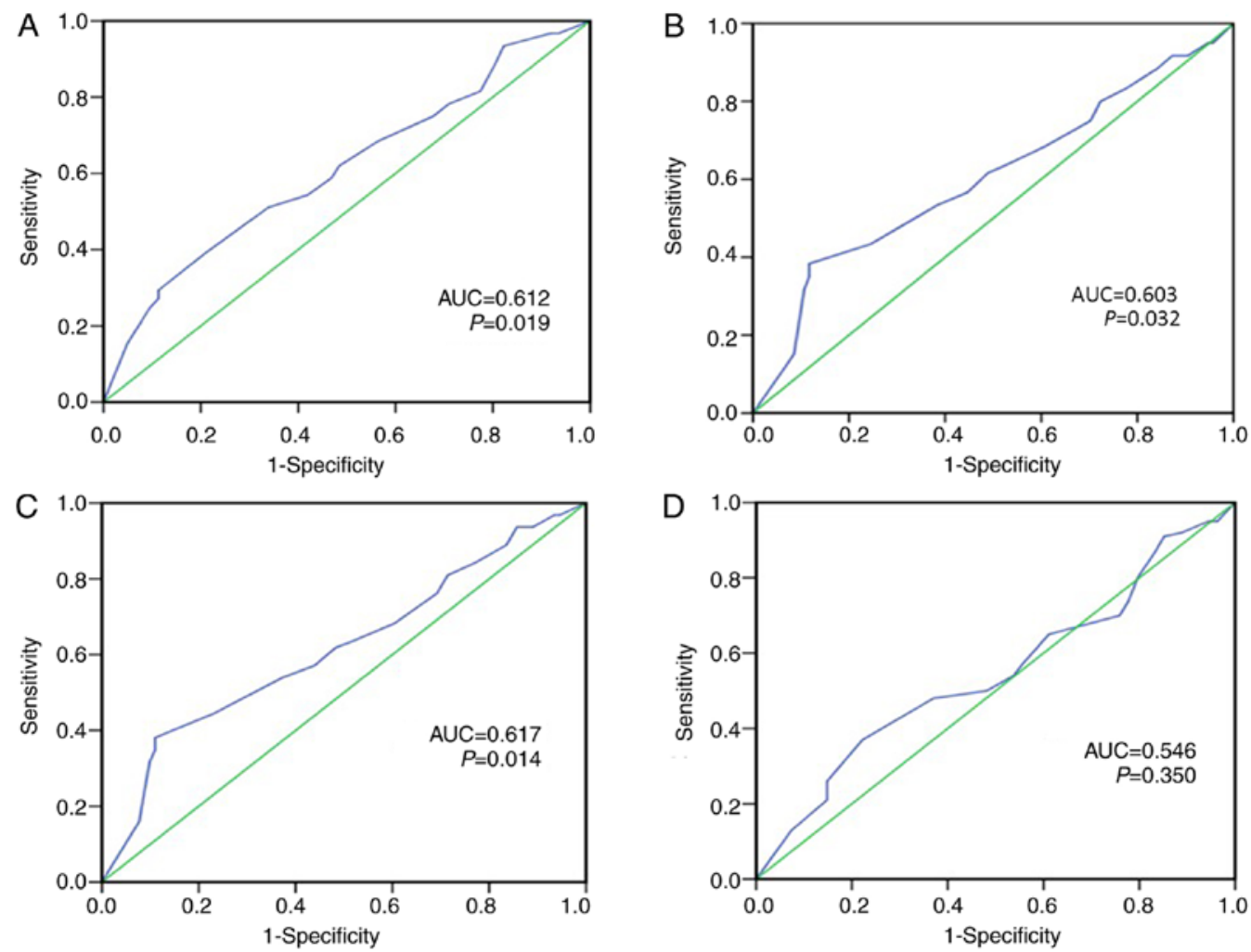

Figure 2. Receiver operating characteristic curve analysis to determine the cut-off value for upregulation of CCL14 protein in the tissues of patients with epithelial ovarian cancer. The sensitivity and specificity for each outcome were plotted: (A) survival status; (B) International Federation of Gynecology and Obstetrics stage; (C) pN status and (D) relapse. AUC, area under the curve; CCL14, C-C motif chemokine 14.

levels of CCL14 protein were defined as those with higher expression levels compared with the cut-off value and low expression levels of CCL14 was defined as those with expression levels which were below the cut-off value.

Association of CCL14 expression levels with clinicopathological features in patients with EOC. The expression levels of CCL14 is associated with a number of clinicopathological features. High expression levels of CCL14 protein were analyzed using the $\chi^{2}$ test which revealed that it was significantly inversely associated with FIGO stage ( $\mathrm{P}=0.014$; Table I). Among 94 patients with advanced stage EOC (III+IV), 71 (75.5\%) had low expression levels of CCL14 and 23 (24.5\%) had high expression levels. Among the 60 patients with early stage EOC (I+II), 34 (56.7\%) had low expression levels and $26(43.3 \%)$ had high expression levels of CCL14. Patients with 
Table I. Association between the clinicopathological variables and expression of CCL14 in patients with epithelial ovarian cancer.

CCL14 expression levels

\begin{tabular}{|c|c|c|c|c|}
\hline & & & & \\
\hline Variable & All cases, $\mathrm{n}$ & Low expression, $\mathrm{n}(\%)$ & High expression, $\mathrm{n}(\%)$ & P-value \\
\hline Age, years & & & & 0.614 \\
\hline$\leq 49$ & 80 & $56(70.0)$ & $24(30.0)$ & \\
\hline$>49$ & 74 & $49(66.2)$ & $25(33.8)$ & \\
\hline FIGO stage & & & & $0.014^{\mathrm{a}}$ \\
\hline $\mathrm{I}+\mathrm{II}$ & 60 & $34(56.7)$ & $26(43.3)$ & \\
\hline III+IV & 94 & $71(75.5)$ & $23(24.5)$ & \\
\hline Histological type & & & & 0.132 \\
\hline Serous & 101 & $73(72.3)$ & $28(27.7)$ & \\
\hline Mucinous & 53 & $32(60.4)$ & $21(39.6)$ & \\
\hline Pathological grade & & & & 0.207 \\
\hline G1 & 27 & $20(74.1)$ & $7(25.9)$ & \\
\hline G2 & 48 & $28(58.3)$ & $20(41.7)$ & \\
\hline G3 & 79 & $57(72.2)$ & $22(27.8)$ & \\
\hline Median tumor size, $\mathrm{cm}$ & & & & 0.271 \\
\hline$\leq 10.05$ & 76 & $55(72.4)$ & $21(27.6)$ & \\
\hline$>10.05$ & 78 & $50(64.1)$ & $28(35.9)$ & \\
\hline Relapse & & & & 0.060 \\
\hline No & 100 & $63(63.0)$ & $37(37.0)$ & \\
\hline Yes & 54 & $42(77.8)$ & $12(22.2)$ & \\
\hline pN status & & & & $0.005^{\mathrm{b}}$ \\
\hline 0 & 63 & $35(55.6)$ & $28(44.4)$ & \\
\hline 1 & 91 & $70(76.9)$ & $21(23.1)$ & \\
\hline $\mathrm{CA} 125, \mathrm{U} / \mathrm{ml}$ & & & & 0.821 \\
\hline$\leq 33$ & 17 & $12(70.6)$ & $5(29.4)$ & \\
\hline$>33$ & 137 & $93(67.9)$ & $44(32.1)$ & \\
\hline CA19-9, U/ml & & & & 0.753 \\
\hline$\leq 35$ & 101 & $68(67.3)$ & $33(32.7)$ & \\
\hline$>35$ & 53 & $37(69.8)$ & $16(30.2)$ & \\
\hline $\mathrm{CEA}, \mu \mathrm{g} / \mathrm{ml}$ & & & & 0.953 \\
\hline$\leq 5$ & 123 & $84(68.3)$ & $39(31.7)$ & \\
\hline$>5$ & 31 & $21(67.7)$ & $10(32.3)$ & \\
\hline
\end{tabular}

${ }^{\mathrm{a}} \mathrm{P}<0.05,{ }^{\mathrm{b}} \mathrm{P}<0.01$. CCL14, C-C motif chemokine 14; FIGO, International Federation of Gynecology and Obstetrics.

pN 1 status had similar results $(\mathrm{P}=0.005$; Table I), $70(76.9 \%)$ had low expression levels and $21(23.1 \%)$ had high expression levels of CCL14. In those patients with pN 0 status, 35 (55.6\%) had low expression levels of CCL14 and 28 (44.4\%) had high expression levels. However, the other clinical and demographic parameters of age, histological type, pathological grade, tumor size, relapse, CA125, CA19-9 and CEA, were not significantly associated with the expression levels of CCL14.

Association between clinicopathological characteristics, CCL14 status and patient survival. To elucidate the best clinicopathological factors for the prognosis of EOC, a univariate analysis of each clinicopathological parameter was performed.
The results demonstrated that patients with high expression levels of CCL14 had a high OS time (mean, 136.1 months); this was significantly higher compared with the mean of 98.9 months in patients with low CCL14 expression levels $(\mathrm{P}=0.026$; Table II; Fig. 3A). A similar trend was observed for progression-free survival (PFS) (Fig. 3B). For FIGO stage, the mean OS time of patients with stage I+II cancer was 155.4 months, which was significantly higher compared with that of patients with stage III+IV cancer (mean, 86.2 months) $(\mathrm{P}<0.001$; Table II; Fig. 3C). PFS of patients with stage I+II EOC was significantly higher compared with that of patients with stage III+IV cancer. $(\mathrm{P}<0.001$; Fig. 3D). For pathological grade, the mean OS time for patients with a high differentiation grade was longer compared 

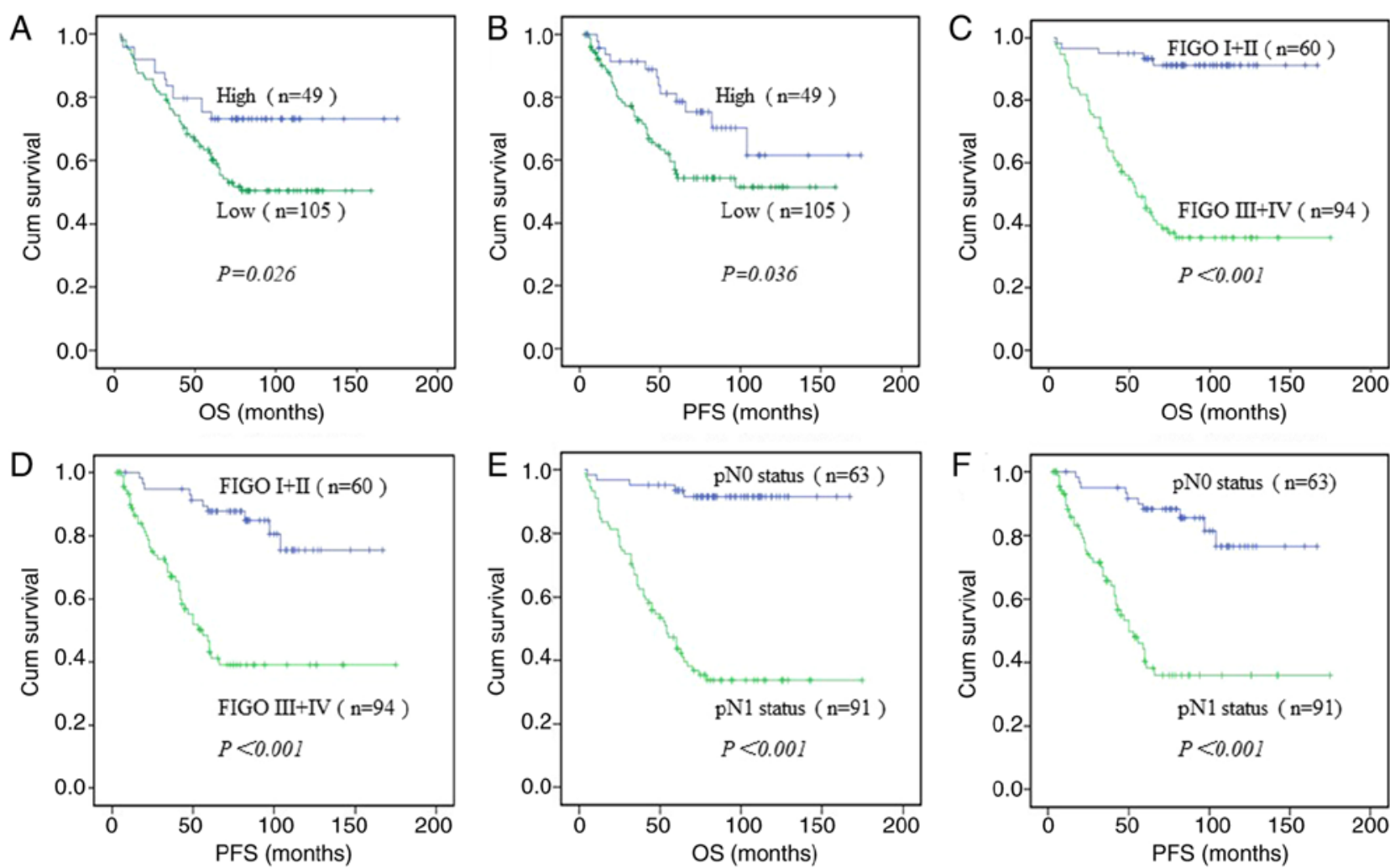

Figure 3. Different prognostic factors affecting OS and PFS time in 154 patients with epithelial ovarian cancer. Each outcome was plotted: (A and B) CCL14 expression levels; (C and D) FIGO stage and (E and F) pN status. OS, overall survival; PFS, progression-free survival; FIGO, International Federation of Gynecology and Obstetrics; cum, cumulative.

with that for patients with a low differentiation grade (G1 mean, 143.3 months; G2 mean, 130.9 months; G3 mean, 90.4 months) $(\mathrm{P}<0.001$; Table II). The mean OS time for relapse was shorter (mean, 73.8 months) compared with that for no relapse (mean, 130.9 months) $(\mathrm{P}=0.001$; Table II). The mean OS time for patients with EOC who had pN 1 status (mean, 83.1 months) was shorter compared with that for patients with $\mathrm{pN} 0$ status (mean, 156 months) ( $\mathrm{P}<0.001$; Table II; Fig. 3E). A similar trend was observed for PFS $(\mathrm{P}<0.001$; Fig. $3 \mathrm{~F})$. The results also revealed that $\mathrm{CA} 125$ is a relevant factor in survival $(\mathrm{P}=0.006$; Table II). However, age, histological type, tumor size, CA19-9 and CEA did not impact the OS time of patients with EOC (Table II).

Independent prognostic factors for patients with EOC. Multivariable analysis using a Cox risk regression model demonstrated that upregulation of CCL14 protein in patients with EOC was significantly associated with OS (HR, 0.483 ; 95\% CI, 0.261-0.896; $\mathrm{P}=0.021$; Table III) and was an independent prognostic factor. Upregulation of CCL14 was also associated with a favorable PFS (HR, 0.437; 95\% CI: 0.228-0.839, $\mathrm{P}=0.013$; Table III). In addition, two interesting phenomena were observed: Pathological grade was an independent prognostic factor in OS (HR, 1.865; 95\% CI, 1.179-2.948; $\mathrm{P}=0.008$; Table III) and PFS (HR, 1.774; 95\% CI, 1.128-2.791; $\mathrm{P}=0.013$; Table III) in the patients with EOC.

\section{Discussion}

Chemokines comprise a group of $\sim 50$ small secreted proteins (8-14 kDa). According to the position of the first 2 cysteine residues, chemokines can be divided into $\mathrm{CC}$-chemokines, CXC-chemokines, C-chemokines and CX3C-chemokines. The role of these proteins is to interact with a family of 20 7-transmembrane G-protein-coupled receptors (24). Some studies have demonstrated that chemokines are novel targets for cancer immunotherapy $(25,26)$. CCL14 is a member of the chemokine family that has attracted considerable attention in recent years, as it has a common receptor (CCR5) against HIV, which may be used as a novel method of treating HIV $(15,27)$. The gene for the CCL14 protein is located on human chromosome 17q11.2 and is the product of transcripts encoding single and double cis-trans and double cis-trans alignments of tandem genes (28). CCL14 is expressed in certain normal somatic tissues, including the spleen, liver, skeletal muscle, myocardium, intestinal tract and bone marrow and is a C-chemokine with unconventional biological activity (14). CCL14 can be converted into a monomer at physiological concentrations, which is able to activate the migration of different leukocytes by inducing $\mathrm{Ca} 2+$ flux (29). Studies have shown that the CCL14/CCR1/CCR5 axis is hypothesized to mediate the chemotaxis of monocytes, eosinophils and T lymphocytes, which is consistent with the high expression levels of CCR5/CCR1 in these cells $(30,31)$.

In the present study, IHC was used to detect the expression levels of CCL14 protein. The results of the current study revealed that CCL14 protein was expressed in most patients with EOC. Upregulation of CCL14 accounted for $43.3 \%$ of those with early-stage EOC, which was a significantly higher percentage compared with that for late-stage patients with EOC $(24.5 \%)$. 
Table II. Univariate analysis of clinicopathological variables in 154 patients with ovarian cancer.

\begin{tabular}{|c|c|c|c|}
\hline Variable & All cases, $\mathrm{n}$ & Mean OS time, months & P-value \\
\hline Age, years & & & 0.057 \\
\hline$\leq 49$ & 80 & $127.19 \pm 7.75$ & \\
\hline$>49$ & 74 & $90.77 \pm 6.76$ & \\
\hline FIGO stage & & & $<0.001^{\mathrm{c}}$ \\
\hline $\mathrm{I}+\mathrm{II}$ & 60 & $155.37 \pm 5.02$ & \\
\hline III+IV & 94 & $86.20 \pm 7.34$ & \\
\hline Histological type & & & 0.413 \\
\hline Serous & 101 & $112.85 \pm 7.08$ & \\
\hline Mucinous & 53 & $113.01 \pm 8.84$ & \\
\hline Pathological grade & & & $<0.001^{\mathrm{c}}$ \\
\hline G1 & 27 & $143.26 \pm 8.60$ & \\
\hline $\mathrm{G} 2$ & 48 & $130.91 \pm 9.96$ & \\
\hline G3 & 79 & $90.38 \pm 7.52$ & \\
\hline Tumor size, $\mathrm{cm}$ & & & 0.897 \\
\hline$\leq 10.05$ & 76 & $116.81 \pm 8.07$ & \\
\hline$>10.05$ & 78 & $96.35 \pm 6.42$ & \\
\hline Relapse & & & $0.001^{\mathrm{b}}$ \\
\hline No & 100 & $130.92 \pm 6.94$ & \\
\hline Yes & 54 & $73.77 \pm 6.12$ & \\
\hline pN status & & & $<0.001^{\mathrm{c}}$ \\
\hline 0 & 63 & $156.00 \pm 4.76$ & \\
\hline 1 & 91 & $83.13 \pm 7.38$ & \\
\hline $\mathrm{CA} 125, \mathrm{U} / \mathrm{ml}$ & & & $0.006^{\mathrm{b}}$ \\
\hline$\leq 33$ & 17 & $119.83 \pm 6.96$ & \\
\hline$>33$ & 137 & $110.06 \pm 6.20$ & \\
\hline $\mathrm{CA} 19-9, \mathrm{U} / \mathrm{ml}$ & & & 0.195 \\
\hline$\leq 35$ & 101 & $106.43 \pm 6.78$ & \\
\hline$>35$ & 53 & $126.78 \pm 9.64$ & \\
\hline $\mathrm{CEA}, \mu \mathrm{g} / \mathrm{ml}$ & & & 0.407 \\
\hline$\leq 5$ & 123 & $109.15 \pm 5.67$ & \\
\hline$>5$ & 31 & $107.49 \pm 13.37$ & \\
\hline CCL14 & & & $0.026^{\mathrm{a}}$ \\
\hline High expression & 49 & $136.06 \pm 9.33$ & \\
\hline Low expression & 105 & $98.86 \pm 6.30$ & \\
\hline
\end{tabular}

${ }^{\mathrm{a}} \mathrm{P}<0.05,{ }^{\mathrm{b}} \mathrm{P}<0.01,{ }^{\mathrm{c}} \mathrm{P}<0.001$. ${ }^{\mathrm{d}}$ Log-rank test. CCL14, C-C motif chemokine 14; FIGO, International Federation of Gynecology and Obstetrics.

The proportion of patients with high expression levels of CCL14 with pN 0 status was higher compared with that of patients with pN 1 status. The mean OS time of patients with high expression levels of CCL14 was significantly higher compared with that of the patients with low expression levels of CCL14. The results revealed that the upregulation of CCL14 was significantly associated with the OS time of patients with EOC. Furthermore, multivariate analysis revealed that the upregulation of CCL14 was significantly associated with OS and PFS time, which indicated that the upregulation of CCL14 was an independent prognostic factor for EOC.

Studies suggest that CCL14 is involved in the incidence and development of breast and oral cancer $(17,18)$; however, there are no reports that investigate the role of CCL14 in EOC. Studies have demonstrated that CCL5/CCR5 and chemokine (C-X-C) motif ligand 12 (CXCL12) $\beta$ promote tumor immune tolerance and tumor progression $(32,33)$. CXCL12/CXCR4, CCL18 and CXCL16/CXCR6 can promote the progression and migration of OC (34-36). However, studies performed on CXCL9 and CXCL10 have revealed that it can promote an antitumor immune response $(37,38)$. These studies have demonstrated that chemokines are directly involved in the formation of the immune microenvironment in OC. CCL14 appears to be significantly downregulated in 9 types of cancer, which implicates CCL14 as an important player in the pathogenesis of cancer (39). Previous studies have demonstrated that CCL14 
Table III. Multivariate survival analyses of clinicopathological variables in patients with epithelial ovarian cancer.

\begin{tabular}{|c|c|c|c|c|c|c|}
\hline \multirow[b]{2}{*}{ Variable } & \multicolumn{3}{|c|}{ OS time } & \multicolumn{3}{|c|}{ PFS time } \\
\hline & HR & $95 \% \mathrm{CI}$ & P-value & HR & $95 \% \mathrm{CI}$ & P-value \\
\hline Age (>49 vs. $\leq 49$ years) & 1.310 & $0.758-2.263$ & 0.333 & 1.027 & $0.579-1.821$ & 0.927 \\
\hline Histological type (serous vs. mucinous) & 1.068 & $0.603-1.892$ & 0.821 & 1.239 & $0.670-2.289$ & 0.494 \\
\hline Pathological grade (G3 vs. G1+2) & 1.865 & $1.179-2.948$ & 0.008 & 1.774 & $1.128-2.791$ & $0.013^{\mathrm{a}}$ \\
\hline Tumor size, $\mathrm{cm}$ (>10.05 vs. $\leq 10.05)$ & 1.118 & $0.654-1.911$ & 0.684 & 0.701 & $0.390-1.258$ & 0.233 \\
\hline $\mathrm{CA} 125, \mathrm{U} / \mathrm{ml}(>33$ vs. $\leq 33)$ & 6.511 & $0.868-48.846$ & 0.068 & 7.126 & $0.946-53.693$ & 0.057 \\
\hline CA19-9, U/ml (>35 vs. $\leq 35)$ & 0.709 & $0.389-1.294$ & 0.263 & 0.841 & $0.447-1.581$ & 0.590 \\
\hline CEA, $\mu \mathrm{g} / \mathrm{ml}(>5$ vs. $\leq 5)$ & 1.158 & $0.617-2.172$ & 0.648 & 1.309 & $0.659-2.60$ & 0.442 \\
\hline CCL14 expression (high vs. low) & 0.483 & $0.261-0.896$ & 0.021 & 0.437 & $0.228-0.839$ & $0.013^{\mathrm{a}}$ \\
\hline
\end{tabular}

${ }^{a} \mathrm{P}<0.05$. CCL14, C-C motif chemokine 14; OS, overall survival; PFS, progression-free survival.

is a factor that can improve the prognosis of patients with hepatocellular carcinoma and human papilloma virus-related cervical intraepithelial neoplasia $(40,41)$. Low expression levels of CCL14 is associated with poor immune function and disease promotion in these carcinomas $(40,41)$. In multiple myeloma, CCL14 can recruit polarized macrophages to form an antitumor immune environment and improve the prognosis of patients with multiple myeloma (42). These studies have also demonstrated that CCL14 is a tumor suppressor gene.

In intestinal studies, CCL14 can recruit chemotactic immune cells and prevent pathogenic bacteria from affecting the intestine (43). This function of CCL14 plays an important anticancer role in OC, since a study demonstrated that there are a large number of macrophages and $\mathrm{T}$ lymphocytes in the OC microenvironment (44). Other studies reported that in OC, macrophages and $\mathrm{T}$ lymphocytes upregulate the expression levels of CCR1 and CCR5 receptors, which creates an antitumor immune environment leading to the necrosis of OC cells $(45,46)$. Furthermore, another study investigating multiple myeloma demonstrated that when CCL14 binds to CCR1 and CCR5, it can lead to chemoattraction and recruitment of macrophages, which promotes proliferation by activating the PI3K-AKT, MAPK/ERK, JNK and p38MAPK pathways (42). These studies suggest that the CCL14 protein is involved in the generation of antitumor immunity. It is possible that CCL14 has a similar role and underlying mechanism in OC, although the mechanism by which it exerts antitumor activities requires further exploration.

In conclusion, CCL14 is an independent prognostic factor in EOC. Upregulation of CCL14 is associated with increased OS and PFS times for patients with EOC. Overall, the present study revealed that CCL14 may be used for the development of novel targeted therapies for EOC.

\section{Acknowledgements}

Not applicable.

\section{Funding}

The present study was supported by grants from the Medical Technology Foundation of Jiangmen (grant no. 2017A4003) and the Guangdong Medical Science and Technology Research Fund (grant no. A2016003).

\section{Availability of data and materials}

The data that support the findings of the present study are available from researchdata.org.cn of Sun Yat-sen University Cancer Center. However, restrictions apply to the availability of these data, which were used under license for the present study and are not publicly available. Data are however available from the authors upon reasonable request and with the permission of Research Data Deposit public platform of Sun Yat-sen University Cancer Center.

\section{Authors' contributions}

YC and JC designed the present study. HH, XC, YC and LH acquired and analyzed the data. YC, YL and $\mathrm{LH}$ performed all the experiments and drafted the manuscript. YX and $\mathrm{ZZ}$ collected and assembled the data and performed the experiments. All authors have read and approved the final manuscript.

\section{Ethics approval and consent to participate}

The study was approved by The Institute Research Medical Ethics Committee of Sun Yat-Sen University Cancer Center (Guangzhou, China) and Jiangmen Central Hospital (Jiangmen, China). The requirement for informed consent (written or verbal) was waived for the use of retrospective data and paraffin tissue specimens from the patients in the present study, the majority of whom were deceased, since this was not deemed necessary by the Ethics Committee. All samples were anonymized.

\section{Patient consent for publication}

Not applicable.

\section{Competing interests}

The authors declare that they have no competing interests. 


\section{References}

1. Siegel RL, Miller KD and Jemal A: Cancer statistics, 2018. CA Cancer J Clin 68: 7-30, 2018

2. Torre LA, Trabert B, DeSantis CE, Miller KD, Samimi G, Runowicz CD, Gaudet MM, Jemal A and Siegel RL: Ovarian cancer statistics, 2018. CA Cancer J Clin 68: 284-296, 2018.

3. Rojas V, Hirshfield KM, Ganesan S and Rodriguez-Rodriguez L: Molecular characterization of epithelial ovarian cancer: Implications for diagnosis and treatment. Int J Mol Sci 17: pii: E2113, 2016

4. McCluggage WG: Morphological subtypes of ovarian carcinoma: A review with emphasis on new developments and pathogenesis Pathology 43: 420-432, 2011.

5. Cancer Genome Atlas Research Network: Integrated genomic analyses of ovarian carcinoma. Nature 474: 609-615, 2011.

6. Kossaï M, Leary A, Scoazec JY and Genestie C: Ovarian cancer: a heterogeneous disease. Pathobiology 85: 41-49, 2018.

7. Morgan RJ Jr, Armstrong DK, Alvarez RD, Bakkum-Gamez JN, Behbakht K, Chen LM, Copeland L, Crispens MA, DeRosa M, Dorigo O, et al: Ovarian cancer, version 1.2016, NCCN clinical practice guidelines in oncology. J Natl Compr Canc Netw 14 $1134-1163,2016$

8. Sant M, Allemani C, Santaquilani M, Knijn A, Marchesi F and Capocaccia R; EUROCARE Working Group: EUROCARE-4 Survival of cancer patients diagnosed in 1995-1999. Results and commentary. Eur J Cancer 45: 931-991, 2009.

9. Sant M, Chirlaque Lopez MD, Agresti R, Sánchez Pérez MJ, Holleczek B, Bielska-Lasota M, Dimitrova N, Innos K, Katalinic A, Langseth H, et al: Survival of women with cancers of breast and genital organs in Europe 1999-2007: Results of the EUROCARE-5 study. Eur J Cancer 51: 2191-2205, 2015.

10. Lei X, Lei Y, Li JK, Du WX, Li RG, Yang J, Li J, Li F and Tan HB: Immune cells within the tumor microenvironment: Biological functions and roles in cancer immunotherapy. Cancer Lett: Nov 12, 2019 (Epub ahead of print).

11. Sonugür FG and Akbulut $\mathrm{H}$ : The role of tumor microenvironment in genomic instability of malignant tumors. Front Genet 10 : 1063, 2019.

12. Mukaida N, Sasaki S and Baba T: Chemokines in cancer development and progression and their potential as targeting molecules for cancer treatment. Mediators Inflamm 2014: 170381, 2014

13. Charo IF and Ransohoff RM: The many roles of chemokines and chemokine receptors in inflammation. N Engl J Med 354: 610-621, 2006

14. Schulz-Knappe P, Mägert HJ, Dewald B, Meyer M, Cetin Y, Kubbies M, Tomeczkowski J, Kirchhoff K, Raida M, Adermann K, et al: HCC-1, a novel chemokine from human plasma. J Exp Med 183: 295-299, 1996.

15. Detheux M, Ständker L, Vakili J, Münch J, Forssmann U, Adermann K, Pöhlmann S, Vassart G, Kirchhoff F, Parmentier M and Forssmann WG: Natural proteolytic processing of hemofiltrate $\mathrm{CC}$ chemokine 1 generates a potent $\mathrm{CC}$ chemokine receptor (CCR)1 and CCR5 agonist with anti-HIV properties. J Exp Med 192: 1501-1508, 2000

16. Tsou CL, Gladue RP, Carroll LA, Paradis T, Boyd JG, Nelson RT, Neote $\mathrm{K}$ and Charo IF: Identification of $\mathrm{C}-\mathrm{C}$ chemokine receptor $1(\mathrm{CCR} 1)$ as the monocyte hemofiltrate $\mathrm{C}-\mathrm{C}$ chemokine (HCC)-1 receptor. J Exp Med 188: 603-608, 1998.

17. Li Q, Shi L, Gui B, Yu W, Wang J, Zhang D, Han X, Yao Z and Shang Y: Binding of the JmjC demethylase JARID1B to LSD1/NuRD suppresses angiogenesis and metastasis in breast cancer cells by repressing chemokine CCL14. Cancer Res 71: 6899-6908, 2011.

18. Feng L, Houck JR, Lohavanichbutr P and Chen C: Transcriptome analysis reveals differentially expressed lncRNAs between oral squamous cell carcinoma and healthy oral mucosa. Oncotarget 8 : 31521-31531, 2017.

19. Kurman RJ, Carcangiu ML, Herrington CS and Young RH: WHO classification of tumours of female reproductive organs. 4th edition. World Health Organization, 2014.

20. Edge SB, Byrd DR, Compton CC, Fritz AG, Greene FL and Trotti A (eds): AJCC Cancer Staging Manual, 7th edition. New York, Springer, 2010.

21. Prat J; FIGO Committee on Gynecologic Oncology: Staging classification for cancer of the ovary, fallopian tube, and peritoneum: Abridged republication of guidelines from the international federation of gynecology and obstetrics (FIGO). Obstet Gynecol 126: 171-174, 2015.
22. Cai MY, Luo RZ, Chen JW, Pei XQ, Lu JB, Hou JH and Yun JP: Overexpression of ZEB2 in peritumoral liver tissue correlates with favorable survival after curative resection of hepatocellular carcinoma. PLoS One 7: e32838, 2012.

23. Cai MY, Zhang B, He WP, Yang GF, Rao HL, Rao ZY, Wu QL, Guan XY, Kung HF, Zeng YX and Xie D: Decreased expression of PinX1 protein is correlated with tumor development and is a new independent poor prognostic factor in ovarian carcinoma. Cancer Sci 101: 1543-1549, 2010.

24. Griffith JW, Sokol CL and Luster AD: Chemokines and chemokine receptors: Positioning cells for host defense and immunity. Annu Rev Immunol 32: 659-702, 2014.

25. Mollica Poeta V, Massara M, Capucetti A and Bonecchi R: Chemokines and chemokine receptors: New targets for cancer immunotherapy. Front Immunol 10: 379, 2019.

26. D'Agostino G, Cecchinato V and Uguccioni M: Chemokine heterocomplexes and cancer: A novel chapter to be written in tumor immunity. Front Immunol 9: 2185, 2018.

27. Münch J, Ständker L, Pöhlmann S, Baribaud F, Papkalla A, Rosorius O, Stauber R, Sass G, Heveker N, Adermann K, et al: Hemofiltrate CC chemokine 1[9-74] causes effective internalization of CCR5 and is a potent inhibitor of R5-tropic human immunodeficiency virus type 1 strains in primary $\mathrm{T}$ cells and macrophages. Antimicrob Agents Chemother 46: 982-990, 2002.

28. Forssmann U, Mägert HJ, Adermann K, Escher SE and Forssmann WG: Hemofiltrate $\mathrm{CC}$ chemokines with unique biochemical properties: HCC-1/CCL14a and HCC-2/CCL15. J Leukoc Biol 70: 357-366, 2001.

29. Blain KY, Kwiatkowski W, Zhao Q, La Fleur D, Naik C, Chun TW, Tsareva T, Kanakaraj P, Laird MW, Shah R, et al: Structural and functional characterization of CC chemokine CCL14. Biochemistry 46: 10008-10015, 2007.

30. Bleul CC, Wu L, Hoxie JA, Springer TA and Mackay CR: The HIV coreceptors CXCR4 and CCR5 are differentially expressed and regulated on human T lymphocytes. Proc Natl Acad Sci USA 94: 1925-1930, 1997.

31. Loetscher P, Uguccioni M, Bordoli L, Baggiolini M, Moser B, Chizzolini C and Dayer JM: CCR5 is characteristic of Th1 lymphocytes. Nature 391: 344-345, 1998.

32. You Y, Li Y, Li M, Lei M, Wu M, Qu Y, Yuan Y, Chen T and Jiang H: Ovarian cancer stem cells promote tumour immune privilege and invasion via CCL5 and regulatory T cells. Clin Exp Immunol 191: 60-73, 2018.

33. Givel AM, Kieffer Y, Scholer-Dahirel A, Sirven P, Cardon M, Pelon F, Magagna I, Gentric G, Costa A, Bonneau C, et al: miR200-regulated CXCL12 $\beta$ promotes fibroblast heterogeneity and immunosuppression in ovarian cancers. Nat Commun 9: 1056,2018

34. Mao TL, Fan KF and Liu CL: Targeting the CXCR4/CXCL12 axis in treating epithelial ovarian cancer. Gene Ther 24: 621-629, 2017

35. Lane D, Matte I, Laplante C, Garde-Granger P, Carignan A, Bessette P, Rancourt C and Piché A: CCL18 from ascites promotes ovarian cancer cell migration through proline-rich tyrosine kinase 2 signaling. Mol Cancer 15: 58, 2016.

36. Hong L, Wang S, Li W, Wu D and Chen W: Tumor-associated macrophages promote the metastasis of ovarian carcinoma cells by enhancing CXCL16/CXCR6 expression. Pathol Res Pract 214: 1345-1351, 2018.

37. Bronger H, Singer J, Windmüller C, Reuning U, Zech D, Delbridge C, Dorn J, Kiechle M, Schmalfeldt B, Schmitt M and Avril S: CXCL9 and CXCL10 predict survival and are regulated by cyclooxygenase inhibition in advanced serous ovarian cancer. Br J Cancer 115: 553-563, 2016.

38. K Au K, Peterson N, Truesdell P, Reid-Schachter G, Khalaj K, Ren R, Francis JA, Graham CH, Craig AW and Koti M: CXCL10 alters the tumour immune microenvironment and disease progression in a syngeneic murine model of high-grade serous ovarian cancer. Gynecol Oncol 145: 436-445, 2017.

39. Wong HS, Chang CM, Liu X, Huang WC and Chang WC: Characterization of cytokinome landscape for clinical responses in human cancers. Oncoimmunology 5: e1214789, 2016.

40. Zhang X, Wan JX, Ke ZP, Wang F, Chai HX and Liu JQ: TMEM88, CCL14 and CLEC3B as prognostic biomarkers for prognosis and palindromia of human hepatocellular carcinoma. Tumour Biol 39: 1010428317708900, 2017.

41. Santegoets LA, van Seters M, Heijmans-Antonissen C, Kleinjan A, van Beurden M, Ewing PC, Kühne LC, Beckmann I, Burger CW, Helmerhorst TJ and Blok LJ: Reduced local immunity in HPV-related VIN: Expression of chemokines and involvement of immunocompetent cells. Int J Cancer 123: 616-622, 2008. 
42. Li Y, Zheng Y, Li T, Wang Q, Qian J, Lu Y, Zhang M, Bi E, Yang M, Reu F, et al: Chemokines CCL2, 3, 14 stimulate macrophage bone marrow homing, proliferation, and polarization in multiple myeloma. Oncotarget 6: 24218-24229, 2015.

43. Kotarsky K, Sitnik KM, Stenstad H, Kotarsky H, Schmidtchen A, Koslowski M, Wehkamp J and Agace WW: A novel role for constitutively expressed epithelial-derived chemokines as antibacterial peptides in the intestinal mucosa. Mucosal Immunol 3 : 40-48, 2010.

44. Negus RP, Stamp GW, Hadley J and Balkwill FR: Quantitative assessment of the leukocyte infiltrate in ovarian cancer and its relationship to the expression of C-C chemokines. Am J Pathol 150: 1723-1734, 1997.
45. Milliken D, Scotton C, Raju S, Balkwill F and Wilson J: Analysis of chemokines and chemokine receptor expression in ovarian cancer ascites. Clin Cancer Res 8: 1108-1114, 2002.

46. Ghoneum A, Afify H, Salih Z, Kelly M and Said N: Role of tumor microenvironment in ovarian cancer pathobiology. Oncotarget 9: 22832-22849, 2018.

(ㄷ)(9) This work is licensed under a Creative Commons EY No ND Attribution-NonCommercial-NoDerivatives 4.0 International (CC BY-NC-ND 4.0) License. 